\title{
Self Awareness Family Initiatives: An Innovative Approach to Social Transformation
}

\author{
Ankwasiize Gabosya Evarist*, Kiyingi Frank Pio, Mawa Michael, Yiga P. Andrew \\ School of Human \& Social Sciences, University of Kisubi (UniK), Uganda
}

Copyright $\bigcirc 2016$ by authors, all rights reserved. Authors agree that this article remains permanently open access under the terms of the Creative Commons Attribution License 4.0 International License

\begin{abstract}
The analyzed self-awareness family initiative is an innovative approach to social transformation. The study was guided by the following objectives that aimed at investigating the psychosocial family transformation approaches, analyzing the initiatives of social transformation and formulating an effective culturally sensitive practice for promoting psychosocial transformation. The study sample size was 217 guided by Documentaries and History Records, Questionnaires and Interviews (In-Depth Key Informant Interviews Semi Structured) guided by the Assessment of Cultural Awareness scale. Findings based on objectives revealed in table 3., 26.27\%; in table 5. $n=112(51.6 \%)$ and in table $6 . n=100(46.1 \%)$ as the highest scores respectively. The study concluded that that every aspect of the family needs to be harmonized with each other within a socially transformative system. The research recommended that therapists and social workers should practice SAFI model as a spring board for understanding and addressing clients' cultural issues.
\end{abstract}

Keywords Self Awareness Family Initiative, Social Transformation

\section{Introduction}

\section{Conceptual Perspective}

Family is the physical smallest and basic unit of a society. It is comprised of father, mother and children. According to Goldenberg et al., (1), a family is a far more than a collection of individuals sharing a specific physical and psychological space. Family is a natural social system that occurs in diversity of forms today and represents a diversity of cultural heritages. In this regard, family entails any two or more persons related by birth, marriage or adoption and residing together as pointed out by Goldenberg et al., (2).Families can be either nuclear or large (extended) and with African families they are mainly large (extended).Hornby (3) asserts that family is a group of people staying in one roof and usually under one head or consisting of one or two parents and their children: the other members of family, close relations/relatives. It can be termed as all the people who are related to each other by blood or by social relations.

In Uganda national development plan (4) a family is still defined as a group which brings together all those who are related by blood that is a man, his wife or wives and children and their grandchildren and great-grandchildren as argued by Kenyatta (5). These are people who are connected biologically. Nyamiti (6) argues that the term "family" in Africa evokes not only blood communal membership of few living members, but also the themes of clan, tribe, affinity, maternity, priesthood, ancestors (involving the themes of mythical time, archetypes, heroes, founders), initiation and hence fecundity, life and power. This involves everyone who is related to a given family. Kayongo-Male and Onyango (7) asserted that the family is the basic and social institution. The family is a foundation and fundamental ground of essential and initial formative place for every human being.

Gichinga (8) emphasized that extended family involves cousins, or anyone nuclear family members such as brothers and sisters, of father and other relatives outside the nuclear family who are maintained through adoption, visiting or economic support and house servants. Shorter (9), defines family as a "Minimal effective group of relatives by blood and/or marriage and analogous groups" (p. 83); (An analogous group means those members who are not related by blood or marriage, for example adopted children). Mbiti (10) says that: "Each person in African traditional life lives in or as a part of the family" (p. 175). Kisembo (11) asserts that:

"the family community was the fundamental element of the African, this basic sphere of action, through which he became integrated with the larger, human community he always acted from within the sphere of the family" ( $p$ p. 202-203).

Shorter (12) sees nuclear family as autonomous and operating without reference to other relatives. The community approaches are essential in building family life in the African family systems. Mbiti (13) says that:

"For African people the family has a much wider circle 
of members than the word suggests in Europe or North America. In traditional society, the family includes children, parents, grandparents, uncles, aunts, brothers and sisters who may have their own children and other immediate relatives" (p.106).

\section{Social Transformation}

Social transformation involves the different ways of social changes that occurs at both large and small scales. Social change entails the transformation of culture and social institutions over time. This is where various social institutions and organizational and cultural structures often seem durable. Williams et al., (14) asserted that transformative social change is a philosophical, practical and strategic process to affect revolutionary change within society that is social transformation.

\section{Theoretical Perspective}

There are different theories used by family therapists. The study was guided by General systems theory. It views organizations as a system consisting of interrelated parts that function in a holistic way to achieve a common.

\section{General Systems Theory}

Barnard (15) showed a unique ability to traverse back and forth between the empirical and theoretical realms and to weave together the latest developments in psychology, sociology, and human relations. This focused on the complexities of the human element in organization, on the psychological forces of human behavior, and on developing ways to manage the complexities of human behavior and to cope with its limitations.

Barnard (16) emphasizes that formal organizations are "organic and evolving social systems" (p.178), and that management's main challenge is achieving cooperation among the groups and individuals within this social system.

Bertanlanffy (17) explains the main contents of an environment that surrounds all systems that includes the following: Closed systems do not interact with the environment. A totally closed system is a convenient theoretical abstraction - all systems are affected to some extent by their environment. Open systems interact with their environment. The environment may impose conditions and contingencies on the system. Conditions: One set of circumstances in the environment, which the system encounters. David (18) advanced that in a dynamic environment the conditions will change with time. Contingency: An unexpected, sharp change in circumstances in the environment, which will disturb the system the system, or place the system under shock.

\section{Ugandan Contextual Perspective}

Psychotherapy programmes and procedures are now a common phenomenon in Uganda. Counsellors, psychiatrists, psychologists, church works, and social and community workers offer some form of counselling services. Amidst counselling services offered by these categories, the family as a basic social unit is jeopardized with psychosocial family rights violations as seen in rampart domestic violence incidences. There was nearly $60 \%$ of women have experienced some form of physical violence, and in more than $87 \%$ of cases, the perpetrator was a current or former husband or partner as explained in 2006 by Uganda Demographic and Health Survey as reflected by UDHS(19).

\section{Statement of Problem}

Professional social workers have employed western family healing approaches for over forty years in Uganda and have been taught in most of the Ugandan Higher Education Institutions as a way of promoting social transformation.

The Ugandan psychotherapists and social workers employ in therapeutic work hinged on Western family social systems such as Psychodynamic approaches as clarified by Becvar \& Becvar (20) Humanistic-existential approaches and Cognitive behavioural approaches.

Despite the above, the Ugandan society has remained with a persistent record of violation of psychosocial family lifestyles argued in UHRC (21).

The researcher wondered on the application of Self awareness family initiatives as appropriate innovative approach to social transformation used to address cultural sensitive family therapy. The study sought to come up with a multicultural family model that creatively fathoms the intricacies of the contemporary Ugandan family as part of the social systems.

\section{Objectives of study}

1. To investigate the psychosocial family transformation approaches in Entebbe -Wakiso Uganda.

2. To analyse the initiatives of social transformation in Entebbe -Wakiso Uganda.

3. To formulate an effective culturally sensitive practice for promoting psychosocial transformation in Entebbe -Wakiso Uganda.

\section{Scope of the Study}

\section{Content Scope of the Study}

The study critically analysed the application of Self awareness family initiatives as appropriate innovative approach to social transformation of the Ugandan families.

\section{Geographical Scope of the Study}

The study was carried out in Entebbe that lies at $0^{\circ} .04 \mathrm{~N}$, $320.280 \mathrm{E}$ and is 37 kilometres South East of Kampala the capital city of Uganda. The results of 2002 population census were 55.086 for Entebbe. The research investigated 592 respondents.

\section{Time Scope of the Study}

The time duration of three years from April 2010 to July 2013 was relevant because politically it was prior to national election that had a lot of social awakening especially the 
issues of socio-economic and cultural rights that affected the fabric of the family set up in Uganda. The period was selected because it was during the time of formulation of the Uganda's vision 2040 that is a social transformation program for the area of study. It is amidst this social awakening that the researchers sought to investigate the issues of social awakening and family awareness in conjunction with their resultant initiative. This time was also the eve for the preparation of national population census that was held in 2014.

\section{Literature Review}

\section{The Psychosocial Family Transformation Approaches}

The psychosocial approaches come from an original form of motivation and training forwarded by Freire (22). Psychosocial approaches worked as an empowering tool of training that magnified individual strength, combining it to create greater horizons and potentials for growth as elaborated by Freire (23). In this psychosocial approach, various tools used to realize social transformation as manifested in the tenet of the biopsychosocial model.

\section{Biopsychosocial Model}

Susan McDaniel, Jeri Hepworth, and Bill Doherty coined the phrase in 1992. The term medical family therapy refers to biopsychosocial treatment of individuals and families who are dealing with medical problems as indicated by Doherty (24). The essential proponents of the Biopsychosocial family therapy entail George Engel, Susan McDaniel, Jeri Hepworth \& William Doherty as described by Engel (25).

Bettocchi (26) elaborated that the bio-psycho-social model is derived from the fundamental initiations by George Engel presenting the interconnectedness between physical, psychological and social well-being in creating a positive health condition of the person.

According to Bettocchi (27) Bio refers to the biological or physical aspects of the person and his/her biological needs that are encompassed in family life; Psycho stands for the psychological elements that refers to feelings, thoughts, attitudes, emotions and are normally understood as "internal" and linked to the mind; Social points to the relation between the person and the "external" world, such as the interactions in the family, at work and in general in the socio-cultural environment as established by Bettocchi (28). The way all these factors interact is complex and the individual is considered as a social actor, who is part of the socio-cultural environment which also contributes, with its presence, to create and modify.

Goldenberg \& Goldenberg (29) elucidates that the family systems therapy uses a bio-psycho-social model that presupposes that problems originate and are sustained in the context of multiple mutually shaping systems. Genetic factors play out in different ways in different contexts and can be modified environmentally by interaction with caretakers.
This is addressed in part by assessing and investigating the following components as elucidated by Goldenberg \& Goldenberg (30): The biological and psychological vulnerabilities which may be involved in problem formation and the transactional processes which sustain the symptoms. Any significant life transitions such as births, deaths, serious illnesses, marriages, divorces which may have affected the child. Families facing the challenges of major illness experience a unique set of biological, psychological and social difficulties that require specialized skills of a therapist who understands the complexities of the medical system, as well as the full spectrum of mental health theories and techniques are reflected in family polling.

Family Polling: Corey (31) shared with us a series of polling questions he uses to assess various aspects of family functioning. (He gave credit to his mentor, William Hiebert, for these questions.) It is clear that this activity draws heavily from the circular questioning methods of Selvini Palazzoli and her colleagues were discussed Palazzoli, Boscolo, Cecchin, \& Prata as proposed by Corey (32). The other techniques used in family therapy as narrated by Deacon \& Piercy (33): cognitive restructuring, active listening, "I" messages, flooding, confronting irrational beliefs, goal-setting, externalizing the problem, scaling, dream interpretation, role-playing, biofeedback, self-disclosure, prescribing the symptom, fogging / negative inquiry and role-modelling. The other techniques include; finding exceptions, level systems, rewards (incentives) / punishments, logical consequences, regression, reframing, identifying triggers, free association, psychodrama. The bio-psycho-social model has got some similarities with the components of techniques used in handling family problems as in the African context through the initiative of social ecological transformation.

\section{The Initiatives of Social Transformation}

The family individuals are in continuous interaction with the existing ecological systems which involve the community and the society. These social ecological systems are mutually interdependent on each other.

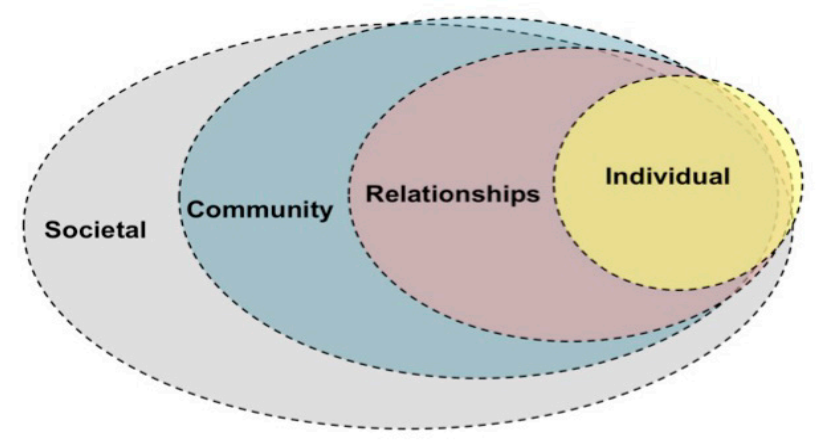

Source: Adapted from Dahlberg \& Krug (34).

Figure1. Initiative of Social Ecology

\section{Individual Domain}

Individual Domain: Centers for Disease Control and 
Prevention. Dahlberg \& Krug (35) pointed out that thequalities, "structures", processes, and paradigms are based on the initiative within the individual reflected in; knowledge, awareness, skills, behaviors (except those that are relational), mental/emotional/physical health, food/housing/financial stability, safety, belief systems (individual norms) and self-efficacy.

\section{Relationship Domain}

Relationship Domain: These are qualities, structures, processes, and paradigms as an initiative that exist in and drive the interaction between two or more individuals. Dahlberg \& Krug (36) asserted that relationships are both formal supports (such as, providers) and informal supports (such as; family, neighbors, friends). Family Initiative is the capacity of family members to develop self reflexivity. Family self reflexivity means the ability of the family members to make themselves and their own behaviours the focus of examinations which permits them to exam themselves and set their goals within the social system.

\section{Community Domain}

Community domain: Tropman et al., (37) advanced that the aspects of community domain are qualities, structures, processes, and paradigms that are located within the collective entity that brings together supporters and builders of protective factors that are relatively close in proximity. Jacoby (38) argued that the definition of community varies among the sites. It may be geographic community, provider community, and/or a special caregiver community (Such as; substance abuse recovery community, domestic violent families and families of children with special needs).

\section{Societal Domain}

Societal Domain: Bronfenbrenner (39) clarified that the societal domain deals with structures and paradigms that institutionalize, regulate, and/or sustain the "systems" in the community, relationship, and individual domains, in support of child abuse and neglect prevention. The societal domain refers to a larger system than the community, most likely a county, state, region within a state, region of the country (multiple states), or nationally and the globe. It is this larger societal domain that is influencing the community domain. These domains influence each other mutually and interdependently.

\section{Culturally Sensitive Practice for Promoting Psychosocial Transformation}

Culture is defined as "...the way people think, feel, and act...' the collective programming of the mind distinguishing the members of one group or category of people from another'....A simpler definition is 'the unwritten rules of the social game' explained by UNESCO (40). UNESCO (41) asserted that "Culture should be regarded as the set of distinctive spiritual, material, intellectual and emotional features of society or a social group, and that it encompasses, in addition to art and literature, lifestyles, ways of living together, value systems, traditions and beliefs." These elements of culture are best comprehended in the stages of cultural cycle that are cyclical than hierarchical. UNESCO (42) identified and explained the application of the five cyclical stages as: Creation involves the originating and authoring of ideas and content. Production entails the reproducible cultural forms (such as TV programmes), infrastructure and processes used in their realization. Dissemination includes the bringing of generally mass-produced cultural products to consumers and exhibitors. Exhibition/Reception/Transmission which refers to the place of consumption and to the provision of live and/or unmediated cultural experiences to audiences by granting or selling access to consume/participate in time-based cultural activities. Consumption/Participation includes the activities of audiences and participants in consuming cultural products and taking part in cultural activities and experiences.

The cyclical nature of culture cycle is a practical way of portraying the inter-connections across these activities, including the feedback processes by which activities (consumption) inspire the creation of new cultural practices and awareness. Bamlett (44) argued that cultural awareness involves a process of self-examination of one's own cultural and professional background and biases towards others and being aware of one's own prejudices that may affect health care delivery. Cultural knowledge is gaining an understanding of the world-views of different cultural and ethnic groups, and seeking information on how diseases and health conditions affect particular groups as addressed Andrulis (45).

The components of effect cultural perceptions include cultural awareness, cultural knowledge, cultural competence and cultural sensitivity for better practices as elaborated by O' Hagan (46).

The consideration of cultural sensitivity in society transformation includes both the culture-generic and culture-specific model. Gerrish \& Papadopoulos (47) developed a set of culturally generic competencies that are applicable across cultural groups as applied in the professional life. The culture-generic competencies: the appreciation of how cultural identity mediates health, or a deeper understanding of the underpinning societal and organizational structures which promote or hinder culturally competent care, help the acquisition of culture-specific competencies, which are particular to specific cultural groups. 


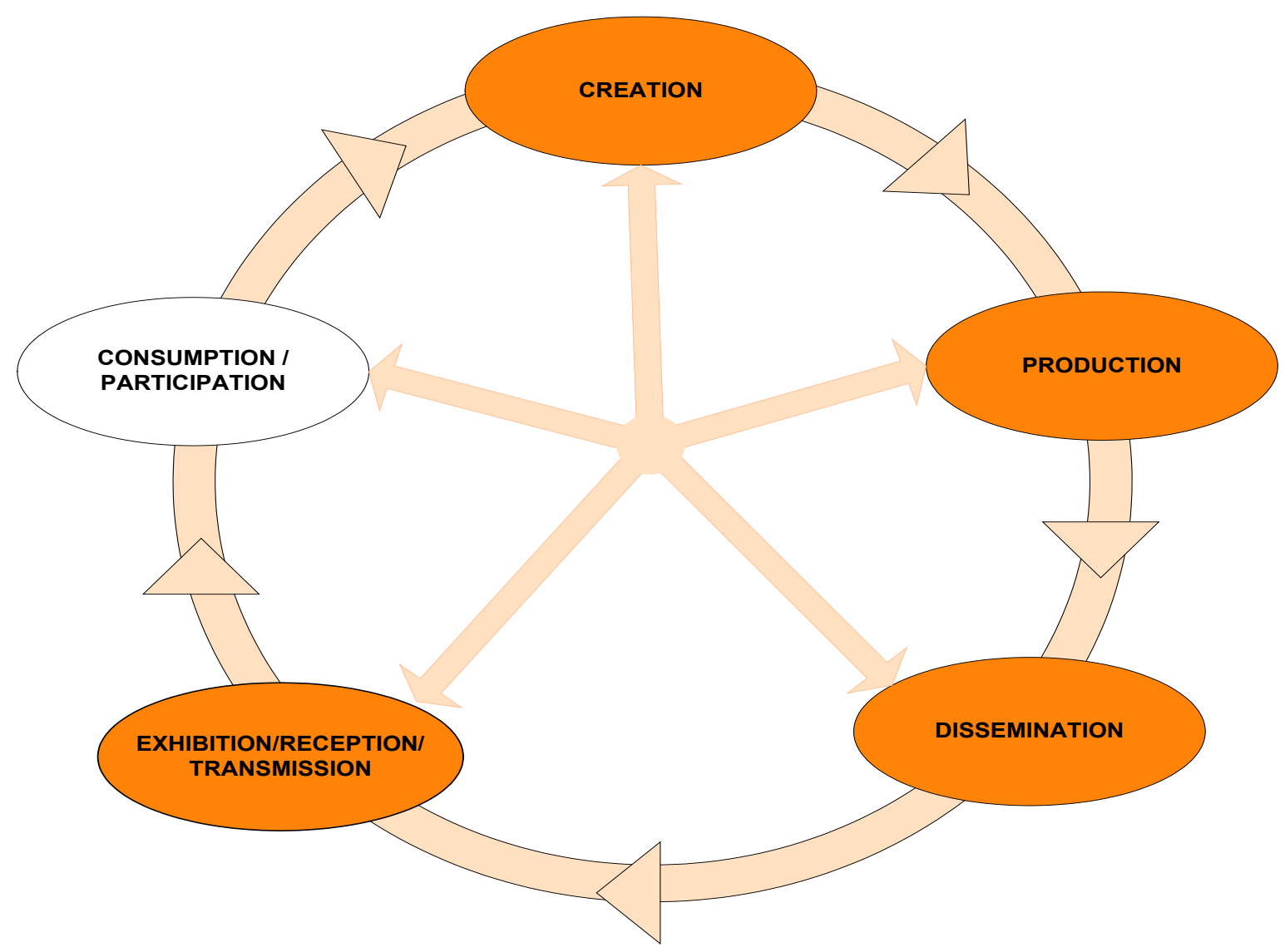

Source: Adapted from UNESCO (43).

Figure 2. Culture cycle

\section{Materials and Methodology}

Exploratory research design: The design assisted the researchers to have a framework for research investigation, analysis and report of the findings. This study employed exploratory research design based on case studies because the researcher intended to intensively assess the effectiveness of family systems therapies in a limited environment to generalize the findings to the entire population as indicated by Mbabazi (48). The reason why a case study was opted for by the research is because it saves the researchers expenditures on time and money and offers enough data for the researchers from the field.

\section{Population}

Wakiso District has a population of 562,609 people according to http://www.google.co.ug accessed on $13 / 3 / 2011$. The final results of the 2002 population census put Entebbe Municipality at a total of 55.086 people of whom 27.135 are males and 27.951 females. The target population of the study was 450 .

\section{Sample size and Selection}

Table 1. Composition of targeted sample size, population category and corresponding sampling method

\begin{tabular}{|c|c|c|c|}
\hline Category & $\begin{array}{c}\text { Sampling } \\
\text { method }\end{array}$ & Target population & $\begin{array}{c}\text { Sampled } \\
\text { Population }\end{array}$ \\
\hline Family heads & $\begin{array}{l}\text { Opportunistic } \\
\text { sampling }\end{array}$ & 48 & 30 \\
\hline $\begin{array}{l}\text { Counselors and } \\
\text { social workers }\end{array}$ & Purposive & 150 & 100 \\
\hline Parent(s) & $\begin{array}{c}\text { Simple } \\
\text { random } \\
\text { sampling }\end{array}$ & 110 & 50 \\
\hline $\begin{array}{l}\text { Children and } \\
\text { Adolescents }\end{array}$ & Snow ball & 90 & 20 \\
\hline \multirow[t]{2}{*}{$\begin{array}{l}\text { Other family } \\
\text { members }\end{array}$} & $\begin{array}{l}\text { Stratified } \\
\text { random } \\
\text { sampling }\end{array}$ & 52 & 17 \\
\hline & Total & 450 & 217 \\
\hline
\end{tabular}

\section{Sample Size and Selection}

Procedures for determining sample size: In this study the sample size will be determined basing on Yamane's (49) formula guidelines for estimating the sample size. The sample size of research participant will calculated basing on Yamane's formulas postulated by Yamane (50).Determining the sample size using Slovene's formula of calculating the sample size as

$$
\mathrm{n}=\frac{\mathrm{N}}{1+\mathrm{N}(\mathrm{e})^{2}}
$$


$\mathrm{n}=$ required sample size, $\mathrm{N}=$ population size, $\mathrm{e}=$ Level of precision 0.05 (error of 5 percentage point) or level of confidence (usually $5 \%$ standard). Therefore $\mathrm{n}=217$

\section{Data Collection Instruments}

The data collection instruments used: Documentaries and History Records, Questionnaires and Interviews (In-Depth Key Informant Interviews Semi Structured) guided by the Assessment of Cultural Awareness scale

\section{Data Quality Control}

Design Validity

The research endeavoured that the instruments used were valid basing on the internal and external validity:The content validity index calculated using the formula below.

$$
\mathrm{CVI}=\frac{\text { No of Items rated as relevant }}{\text { Total number of items in questionnaire }} \times 100 \%
$$

The cumulative content validity index from three blind expert researchers scored the following CVI: $\mathrm{CVI}=\frac{28}{30} \times$ $100 \%$

$$
\mathrm{CVI}=93.3 \%, \mathrm{CVI}=93 \% . \text { Therefore, } \mathrm{CVI}=0.93
$$

Therefore, the instruments were confirmed valid as their corresponding CVIs calculated results were within the acceptable range of 0 to 1 . The CVI results for the questionnaires were established at 0.93 which is $>0.5$ but $<$ 1.

\section{Reliability of Data Collection Instruments}

The reliability of the data collected will be tested using Cronbach's alpha was determined and calculated using the formula below:

$$
\alpha=\frac{N \cdot \bar{c}}{\bar{v}+(N-1) \cdot \bar{c}}
$$

Where $\mathrm{N}$ is equal to the number of items, c-bar is the average inter-item covariance among the items and v-bar equals the average variance.

Table2. Reliability Statistics

\begin{tabular}{|c|c|}
\hline Cronbach's Alpha & N of Items \\
\hline .743 & 22 \\
\hline
\end{tabular}

The above table.2 depicts that the reliability of the instruments was acceptable. The alpha coefficient for the twenty-two items was .743( $\approx 74.3 \%)$, which suggests that the items have relatively high internal consistency.

\section{Data Analysis}

The qualitative data was analysed using content analysis while quantitative data was analysed using statistical data analysis. The collected data was classified and tabulated in accordance with the objectives to arrive at the meaningful and relevant inferences by using thematic data analysis and statistical data analysis techniques.

\section{Findings}

\section{Findings on the Psychosocial Family Approaches}

Biopsychosocial Family Therapy

Table 3. Suggests the components of the biopsychosocial family model used to enhance social transformation

\begin{tabular}{|c|c|c|}
\hline $\begin{array}{c}\text { What are the components of the } \\
\text { biopsychosocial family model used to } \\
\text { enhance social transformation? }\end{array}$ & Frequency & Percentage \\
\hline Biological and psychological vulnerabilities & 35 & 16.13 \\
\hline Any significant life transitions & 40 & 18.43 \\
\hline Family member adjusted to these transitions & 45 & 20.74 \\
\hline Adult difficulties with these transitions & 40 & 18.43 \\
\hline All the above & 57 & 26.27 \\
\hline Total & 217 & 100 \\
\hline
\end{tabular}

Source: Field data (2014).

In table.3,26.27\% of the respondents indicated that all the named options were key biosocial family model used to enhance social transformation. The highest option was all the above with 26.27, while the lowest choice was Biological and psychological with $16.13 \%$.

Table4. The biopsychosocial model is used by family therapists to deal with social transformation

\begin{tabular}{|c|c|c|}
\hline $\begin{array}{c}\text { The biopsychosocial model is used by } \\
\text { family therapists to deal with social } \\
\text { transformation }\end{array}$ & Frequency & Percentage \\
\hline Strongly agree & 39 & 18.0 \\
\hline Agree & 55 & 25.3 \\
\hline Not sure & 48 & 22.1 \\
\hline Disagree & 45 & 20.7 \\
\hline Strongly disagree & 30 & 13.8 \\
\hline Total & 217 & 100.0 \\
\hline
\end{tabular}

Source: Field data (2014)

According to table.4 about whether the biopsychosocial model is used by family therapists to deal with social transformation disclosed that the highest scores were on agree with $n=55(25.3 \%)$, while those with lowest scores were strongly disagree with $n=30(13.8 \%)$. The cumulative percentage of agreement scores was $43.3 \%$ derived from those who strongly agree with $18.0 \%$ and those who agreed with $25.3 \%$, whereas the lowest cumulative score was $34.5 \%$ derived from disagree scores of $20.7 \%$ and strongly disagree scores of $13.8 \%$. However, those who were not sure score $\mathrm{n}=48(22.1 \%)$. 
The Initiatives of Social Transformation

Table 5. The Initiatives of social transformation

\begin{tabular}{|c|c|c|}
\hline $\begin{array}{c}\text { The initiatives of social } \\
\text { transformation enhance } \\
\text { SAFI by family therapists }\end{array}$ & Frequency & Percentage \\
\hline Strongly agree & 112 & 51.6 \\
\hline Agree & 56 & 25.8 \\
\hline Not sure & 25 & 11.5 \\
\hline Disagree & 20 & 9.2 \\
\hline Strongly disagree & 4 & 1.8 \\
\hline Total & 217 & 100.0 \\
\hline
\end{tabular}

Source: Field data (2014)

According to the findings in table. 5 about if the initiatives of social transformation enhance SAFI by family therapists the highest scores were on agree with $n=112(51.6 \%)$, while those with lowest scores were strongly disagree with $n=4$ $(1.8 \%)$. The cumulative percentage of agreement scores was $77.4 \%$ derived from those who strongly agree with $51.6 \%$ and those who agreed with $25.8 \%$, whereas the lowest cumulative score was $11.0 \%$ derived from disagree scores of $9.2 \%$ and strongly disagree scores of $1.8 \%$. However, those who were not sure score $n=25(11.5 \%)$.

An Effective Culturally Sensitive Practice for Promoting Psychosocial Transformation

Table6. Culturally sensitive practice for promoting psychosocial transformation

\begin{tabular}{|c|c|c|}
\hline $\begin{array}{c}\text { A culturally sensitive practice } \\
\text { promotes psychosocial } \\
\text { transformation }\end{array}$ & Frequency & Percentage \\
\hline Strongly agree & 100 & 46.1 \\
\hline Agree & 39 & 18.0 \\
\hline Not sure & 33 & 15.2 \\
\hline Disagree & 28 & 12.9 \\
\hline Strongly disagree & 17 & 7.8 \\
\hline Total & 217 & 100.0 \\
\hline
\end{tabular}

Source: Field data (2014)

According to the result in table. 6 about if the initiatives of social transformation enhance SAFI by family therapists the highest scores were on agree with $n=100$ (46.1\%), while those with lowest scores were strongly disagree with $n=17$ $(7.8 \%)$. The cumulative percentage of agreement scores was $64.0 \%$ derived from those who strongly agree with $46.1 \%$ and those who agreed with $18.0 \%$, whereas the lowest cumulative score was $20.7 \%$ derived from disagree scores of $12.9 \%$ and strongly disagree scores of $7.8 \%$. However, those who were not sure score $n=33(15.2 \%)$.

\section{Discussion of Findings}

\section{Psychosocial Family Transformation Approaches in Entebbe -Wakiso Uganda}

The findings in table.3 about the component of psychosocial approach used to enhance social transformation had the highest option of "all the above" with $26.27 \%$. This option is in line with Engel (51) who postulated a Biopsychosocial Model of Illness in the family and society. This model integrates Biological, Psychological and Social factors into the etiology and treatment of illness in the family and society as postulated by Engel (52).

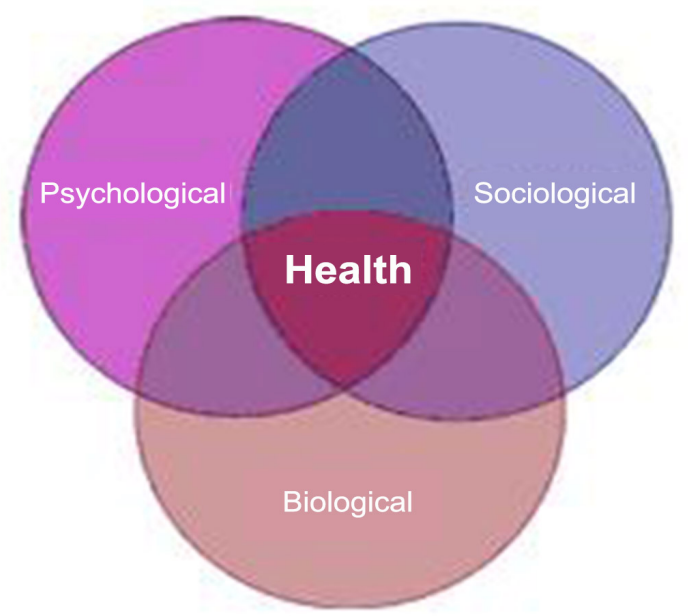

Source: Adapted from George Engel (53)

Figure 3. The physical, psychological and social factors impacting on individual's health within a family setting.

This model recognizes that psychosocial factors such as beliefs, relationships and stress greatly impact progression and recovery of illness and disease various family members. George Engel (54) argued that it is incumbent of the therapists address the psychosocial factors in conjunction with the biological pathology. The biopsychosocial approach of Engel is reflected in the family ecological perspective.

The results in table. 4 about use of biopsychosocial model by family therapists to deal with social transformation are in agreement with the usage of the biopsychosocial model as manifested in holism. The term 'holism' was coined by philosopher Jan Smuts in 1926, derived from the Greek hólos, meaning 'whole' as pointed out by Jan Christiaan Smuts (55). Applied to healthcare, holism is the art and science of caring for a person in a way which considers all aspects of their body, mind, spirituality and emotional state in relation to "[other] individuals, the environment, or populations, either separately or in various combinations" as discussed by C, L. \& W. G, (56). The biopsychosocial model emphasized the three domains of human life that is the physical (biological), psychological and social.

\section{Initiatives of Social Transformation in Entebbe -Wakiso Uganda}

The results in table. 5 concerning initiatives of social transformation used in SAFI by family therapists are in agreement with Krishna \& Anirudh's (57) process of social transformation passes through community, civil society and government as reflected in the figure. 4 below. 


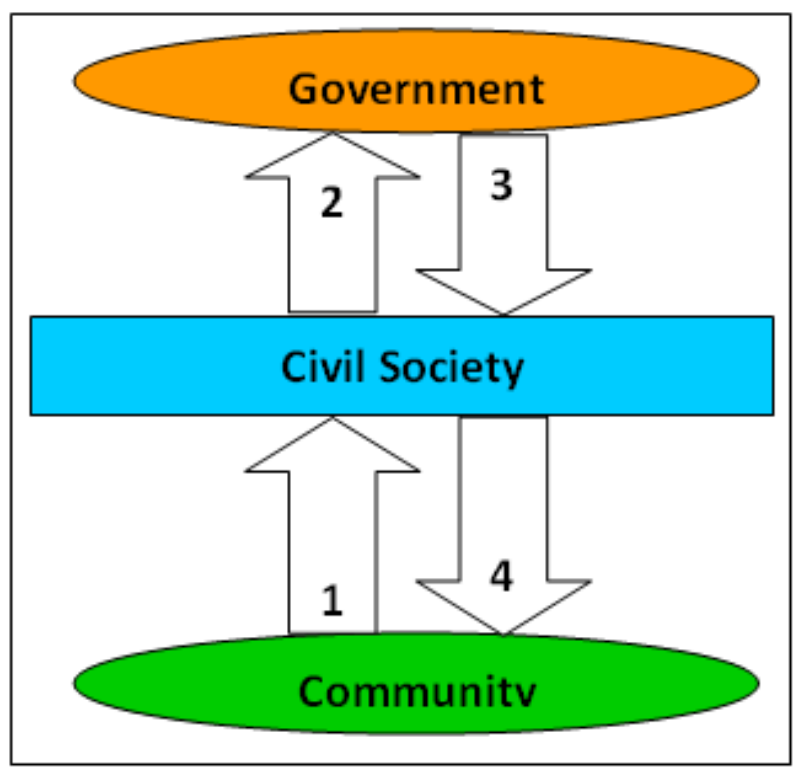

Source: Adopted from Krishna, Anirudh (58).

Figure 4. The interactive nature community, Civil Society and government

As in figure.4, for proper participatory societal transformation to transpire has to pass through three major agents of community, civil society and the government that must be in mutual collaboration and dialogue. The action for change should start from the effort of the grass root community members the efforts of the civil society to the guidance of the government. The societal enduring dialogical capacities between community, civil society and government are in line with the collective capabilities of the involved actors that are always interface with each other as a means of facilitating interest formation, aggregation and representation as asserted by Krishna, Anirudh (59). The intertwining relationship between the community, civil society and government is an essential benefit resource for societal transformation.

\section{Culturally Sensitive Practice for Promoting Psychosocial Transformation in Entebbe -Wakiso Uganda}

The findings in table. 6 about culturally sensitive practice that promote psychosocial transformation of the option strongly agree with $n=100(46.1 \%)$ are in concurrence with the interactional development continuum as in figure.7. Bennett's (60) assertions on the underlying assumption “....as one's experience of cultural difference becomes more complex and sophisticated, one's competence in intercultural relations increases..."

Bennett (61) presented competencies of intercultural relations that include: Denial, Defense, Minimization, Acceptance, Adaptation and Integration.

\section{Intercultural Development Continuum}

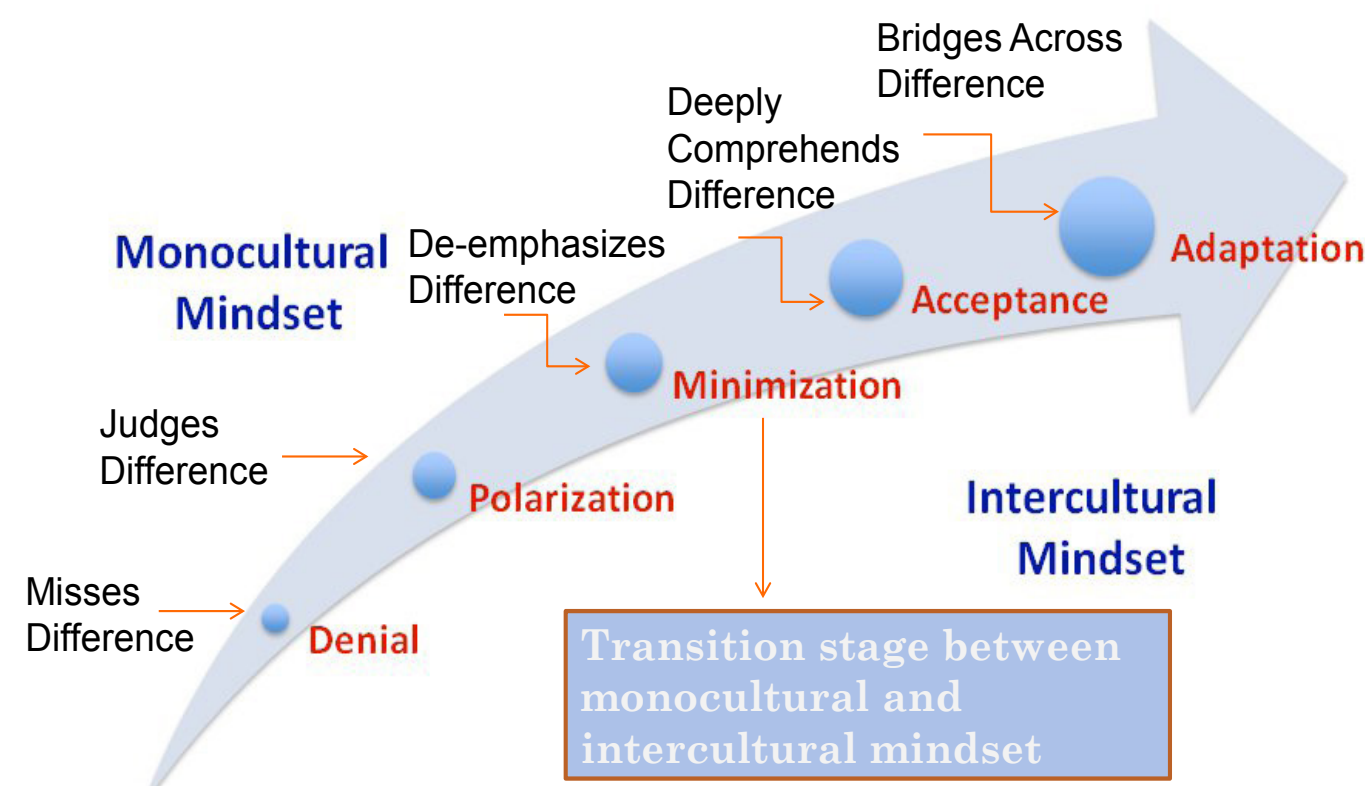

Source: Reproduced from the Intercultural Development Inventory Resource Guide by permission of the author, Mitchell R. Hammer, Ph.D., IDI, LLC. Copyright 1998, 2003, 2007, 2012 Mitchell R. Hammer, IDI, LLC. All Rights Reserved.

Figure 5. The intercultural development continuum 


\section{Contribution to New Knowledge Based on SAFI Model}

SAFI Model draws its philosophical praxis from the Xhosa expression umuntu ngumuntu ngabanye Bantu, meaning that each individual's humanity is ideally expressed in relationship with others and, in turn, individuality is truly expression of one's own being, but also of one's duties towards one's neighbour.

SAFI Model is an indigenous based approach on African philosophy that treats all people as human beings and considers the human being as the foremost priority in all conduct. It teaches sharing and respect for all people as proposed by Bhengu (62). The concept is tied to one's personal identity and is intrinsic to this 'Community-oriented outlook. SAFI Model is a powerful therapeutic approach deriving values from the African philosophy of teamwork and collaboration that has the power to reshape our workplaces, our relationships with our co-workers, and our personal lives and families. A person is viewed as one intimately integrated into a family and social system. The indigenous aspects in the SAFI model are reflected in inter-subjective axiology.

\section{SAFI as Inter-subjective Axiology (the Ethics of Acting in 'Togetherness')}

SAFI has Inter-subjective Axiology. These thoughts have been much inspired by the arguments on togetherness as developed by Ssekate (63) that the 'being-in-common' of the community of the living or the relational ethics is a foundational element for any inter-subjective praxis which is based on the commonality of life that is identical in them all.

It is due to the inter-subjective axiological experience, that the individual living human person (self) does not act in relation with the 'other' as if he were a monadic ego saturated by self-sufficiency, but as a member of the living unity. From this background, Henry (64) argues what ought to be the authentic pathetic axiology for the inter-subjectivity which in essence implies acting-in-communion-with, even if each individual member of the living community acts independently. This independent acting within the transcendental illusion is contrally to the SAFI's interconnectivity element and is the root of the ego-centric tendencies.

\section{SAFI's Phenomenological and a Guardianship Dimensions}

SAFI model is phenomenological because it bases its operation and employability on the nature of the lived experience. Manen (65) argued that a phenomenological human science begins in lived experience and eventually turns back to it. Manen (66) quotes Dilthey (1985) to have suggested that in its basic form lived experiences involves our immediate, pre-reflective consciousness of life; a reflective or self-given awareness which is, awareness, unaware of itself.

Manen (67) noted that lived experience first of all has a temporal structure; it can never be grasped in its immediate manifestation but only reflectively as past presence. Lived experience is the starting point and the end point of phenomenological research. The aim of phenomenology is to transform lived experience into a textual expression of its essence-in such a way that the effect of the text is at once a reflective re-living and a reflective appropriation of something meaningful: a notion by which a person is powerfully animated in his or her own lived experience.

SAFI model has a guardianship dimension in the sense creating a sense of responsibility for each other as family members. This involves taking care of bio-psychosocial needs of each family member. The family therapist is in turn empathetically with a sense of responsibility for the healing and growth process each of the family members.

One could describe the happenings phenomenological and guardianship dimensions at five levels as suggested by Cassano (68); within families (intra-family); between families (inter-family); between clinicians, families and their individual members (therapist-client); within large group which is composed of families and clinicians (intra-group) and between families, clinicians, the group and wider context (extra-group).

All the above psychogenesis elements provoke insights of self-awareness and self-initiation of desired life style conceptualized in self-receptivity, self-actuality and self-interconnectivity.

SAFI Model postulates three interlocking concepts of receptivity, actuality and interconnectivity that clothed (wrapped) within community dialogue.

Actuality: Every family member taking it as one's responsibility to offer a valued time to the family issues, to share the gifts and potentialities and also to care for each family member in need. In so doing, the family experiences the ultimate contribution for each member and this builds up harmony and growth of the family system

Family Receptivity as an interactive nature of family members guided by the readiness to attend, follow and respond to family issues. In this way, the family members exercise their duty and responsibility towards concerns of the entire family. This family respectability becomes the basis of family harmony and dynamic growth. The interconnectivity approach therefore is rooted in the biopsychosocial model of George Engel who is cited in by Bettocchi (69).

The researchers came up with a flexible framework for action purposes. Action leads to a new reality and new experience to be examined. The major elements within the SAFI Action framework are known as: Experience or contact; Social analysis or simply analysis; Family Ideals and Family planning or response. 


\section{RELATIONAL ETHICS}

\section{(An intra and inter subjective axiology)}

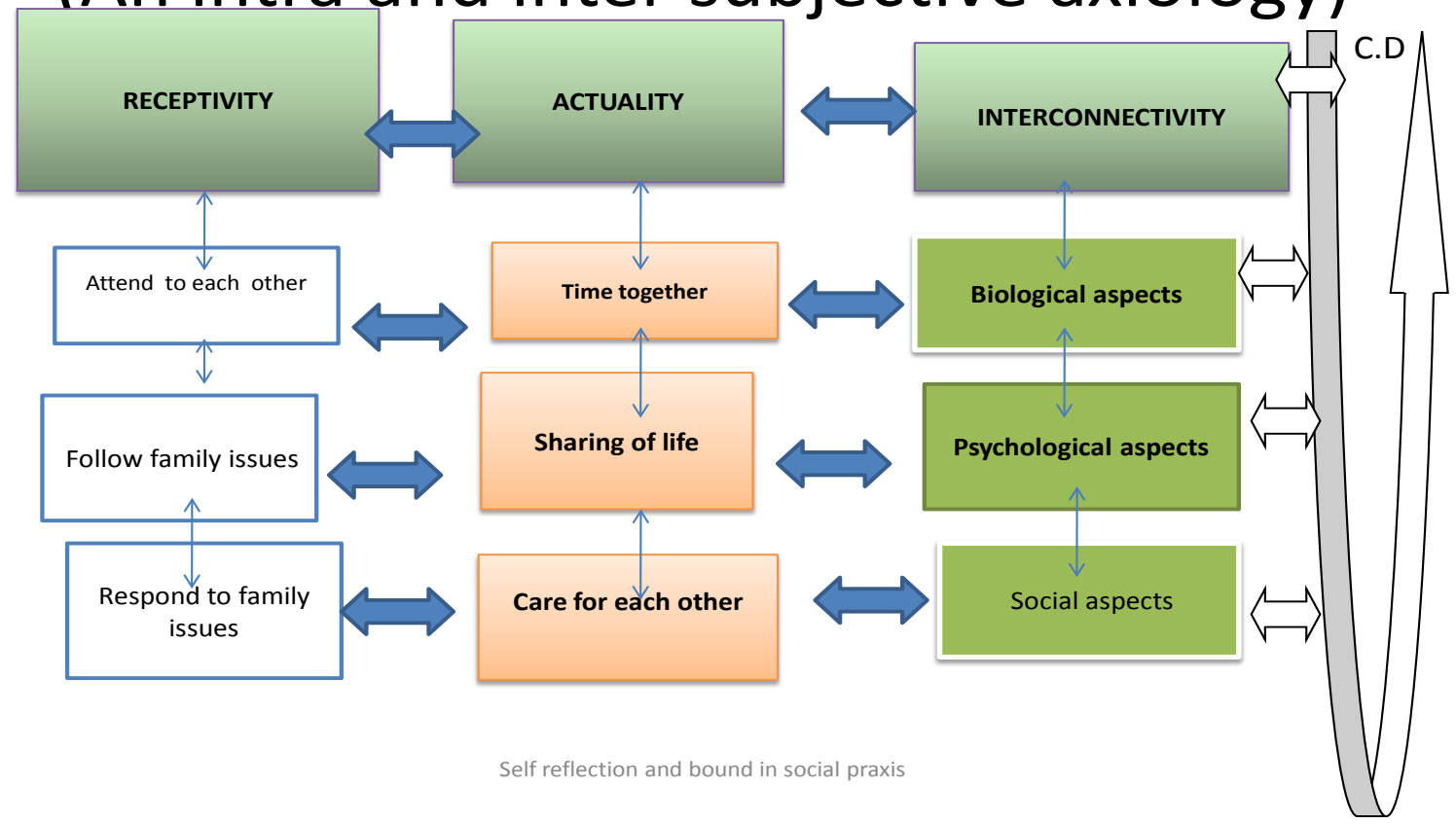

\section{SAFI Therapeutic Spiral}

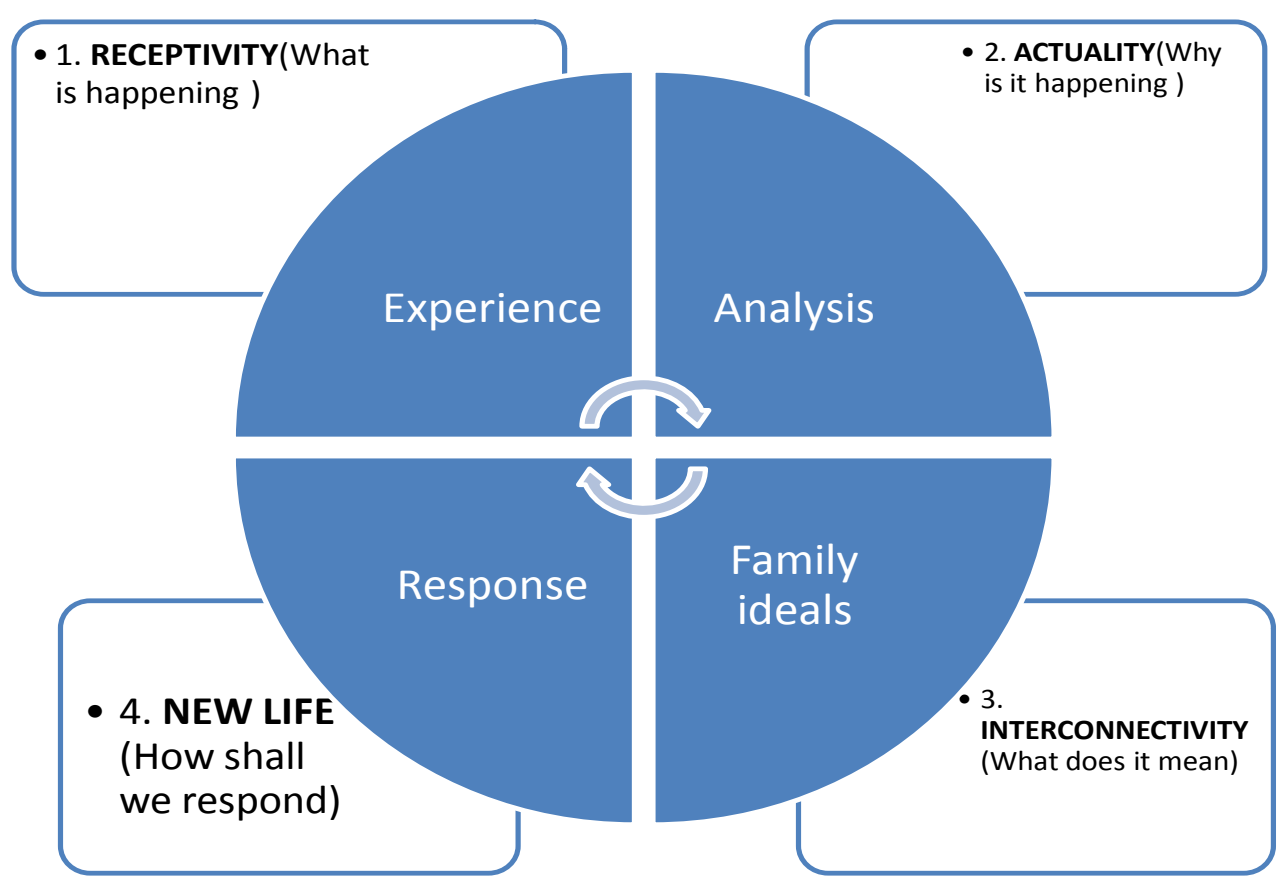

Source: Researchers (2012)

Figure 7. SAFI Therapeutic Spiral 
This therapeutic spiral is holistic, engaging family thinking, feeling and action. It touches on the cognitive or intellect, as well as affectivity and the effective or deliberative aspects. Experience and analysis help family members to achieve better understanding-using our heads. Immersion or contact in the experience of the moment can also help family members get in touch with feelings - using our hearts. Family ideals reflection helps family members to get in touch with deeper values - aligning our heads and our hearts together. Planning for improved responses to issues and situations involves acting upon the situations at hand.

\section{Conclusions}

The researchers' major conclusion is that every aspect of the family needs to be harmonized with each other and not departmentalized and fragmented into portions and pieces as if one thing has to be done as the other is suspended for a moment. This is because family life is not a fragment of dismembered issues but a unified system.

The study recommends that therapists of today need to harmonize cultural values, beliefs and practices when making therapeutic interventions. The research further recommended that the therapists and social workers should practice SAFI model as a spring board for understanding and addressing clients' cultural issues.

\section{REFERENCES}

[1] Goldenberg, I. \& Goldenberg, H. Counselling today's families (4th edition). Pacific Grove, CA: Brooks, 2002.

[2] Goldenberg H., Goldenberg I. Family Therapy: An Overview ( $8^{\text {th }}$ ed.). USA: Brooks/Cole, 2012.

[3] Hornby A. S, Oxford Advanced Learner's Dictionary (New $7^{\text {th }}$ edition), London, Oxford University, 2007.

[4] Uganda national development plan, 2011-2015.

[5] Kenyatta Jomo, Facing Mount Kenya, London-United Kingdom, Martin Secker and Warburg Ltd/Kingsway, 2000.

[6] Nyamiti Charles, Approaches to African Theology, 'Maryknoll, NY, Orbis Books, 1987.

[7] Kayongo-Male D and Onyango P, The Sociology of the African Family, Longman, London-UK, 1994.

[8] Gichinga M. E., Counselling in the African context: A counselling Guide, GEM counselling services, Nairobi-Kenya, 2007.

[9] Shorter, A., African Culture An overview, Pauline Publications, Nairobi, 1998.

[10] Mbiti, J., African Religions and Philosophy, Heineman Educational Books, Ltd, London, 1969.

[11] Kisembo B. Magesa L. and Shorter A, African Christian Marriage, (2nd ed.), Paulines Publications, Nairobi, 2010.
[12] Shorter, A, African Christian Theology, Geoffrey Chapman, London, 1975.

[13] Mbiti, J., S. (Ed.) African Religions and Philosophy, Heinemann, London, 1990.

[14] Williams, Angel Kyodo; Gass, Robert; Horwitz, Claudia; Vega-Frey, Jesse; Maina, Ng'ethe; Haines, Staci K.; Movement Strategy Center. "Framing Deep Change: Essays on Transformative Social Change". Third Way Press. p. 4, 2010 .

[15] Barnard, C. I. The Functions of the Executive, Harvard University Press. Cambridge (MA), 1938.

[16] Barnard, C. I, Organization and Management: Selected Papers, Harvard University Press, Cambridge, MA, 1948.

[17] Bertalanffy, L. von, Untersuchungenüber die Gesetzlichkeit des Wachstums. I. Allgemeine Grundlagen der Theorie; mathematische und physiologische Gesetzlichkeiten des Wachstumsbei Wassertieren. Arch. Entwicklungsmech., 131:613-652, 1934.

[18] David Pouvreau. "Une histoire de la 'systémologiegénérale' de Ludwig von Bertalanffy - Généalogie, genèse, actualisation et postérité d'un projetherméneutique", Doctoral Thesis (1138 pages), Ecole des Hautes Etudes en Sciences Sociales (EHESS), Paris: http://tel.archives-ouvertes.fr/tel-0 0804157, 2013.

[19] Uganda Demographic and Health Survey, Uganda, Kampala, 2006.

[20] Becver D. S., \& Becver, R. J, Family Therapy: A Systematic Integration. Boston. Allyn and Bacon, 2000.

[21] Uganda Human Rights Commission: $15^{\text {th }}$ Annual Report. Kampala-Uganda, 2012.

[22] Freire Paulo and Antonia. Learning to Question, The Continuum Publishing Company, New York, 1989.

[23] Freire, P, Pedagogy of the Oppressed: Harper Collins, New York, 1994.

[24] Doherty, W., J, Family Therapy Goes Post Modern. Family Net-worker, 15(5), 36-42, 1991.

[25] Engel, George L. The need for a new medical model: A challenge of biomedicine" science Journal 196:129-136, 1977.

[26] Bettocchi Guillermo, Social Counselling and Social Work with Clients and Their Families in the Somali Context, A facilitator's guide, Somali, 12UNHCR The UN Refugee agency, 2009.

[27] Bettocchi Guillermo, Social Counselling and Social Work with Clients and Their Families in the Somali Context, A facilitator's guide, Somali, 12UNHCR The UN Refugee agency, 2009.

[28] Bettocchi Guillermo, Social Counselling and Social Work with Clients and Their Families in the Somali Context, A facilitator's guide, Somali, 12UNHCR The UN Refugee agency, 2009.

[29] Goldenberg, I. \& Goldenberg, H, Family Therapy: an overview (3rd Ed.), CA: Brooks/ Cole, Monterey, 1996.

[30] Goldenberg, I. \& Goldenberg, H, Family Therapy: an overview (3rd Ed.), CA: Brooks/ Cole, Monterey, 1996. 
[31] Corey G, Theory and Practice of Counselling and Psychotherapy. ( $8^{\text {th }}$ Edn.) USA, 2009.

[32] Corey, G, Theory and practice of group counselling (6th ed.). Belmont, CA: Brooks/Cole-Thomson Learning, 2004.

[33] Deacon A. Sharon and Piercy P. Fred. Qualitative Methods in Family Evaluation, Routledge, London, 2001.

[34] Dahlberg LL, Krug EG, Violence-a global public health problem. In: Krug E, Dahlberg LL, Mercy JA, Zwi AB, Lozano R, eds. World Report on Violence and Health. Geneva, Switzerland: World Health Organization, 2002.

[35] Dahlberg LL, Krug EG, Violence-a global public health problem. In: Krug E, Dahlberg LL, Mercy JA, Zwi AB, Lozano R, eds. World Report on Violence and Health. Geneva, Switzerland: World Health Organization, 2002.

[36] Dahlberg LL, Krug EG, Violence-a global public health problem. In: Krug E, Dahlberg LL, Mercy JA, Zwi AB, Lozano R, eds. World Report on Violence and Health. Geneva, Switzerland: World Health Organization, 2002.

[37] Tropman John E., Erlich, John L. and Rothman, Jack, "Tactics and Techniques of Community Intervention," Wadsworth Publishing, 2006.

[38] Jacoby Brown, Michael, Building Powerful Community Organizations: A Personal Guide To Creating Groups That Can Solve Problems and Change the World, Long Haul Press, 2006.

[39] Bronfenbrenner Urie, Making Human Beings Human: Bioecological Perspectives on Human Development. Sage Publications, 2004.

[40] UNESCO-UIS, Creating Global Statistics for Culture: Expert Scoping Study. Paper submitted to the UIS by BOP Consulting, 2006a.

[41] UNESCO, The UNESCO Framework for Cultural Statistics. Statistical Commission and Economic Commission for Europe, UNESCO, Conference of European Statisticians. Third Joint Meeting on Cultural Statistics, 17-20 March 1986. CES/AC/44/11, 1986.

[42] UNESCO, Universal Declaration on cultural diversity. Paris: UNESCO, 2001.

[43] UNESCO-UIS. Guidelines for Measuring Cultural Participation, Paper submitted to the UIS by Adolfo Morrone, UNESCO Institute of Statistics, Montreal, 2006b.

[44] Bamlett, M, Translating What We Know Into What We Do. Creating Culturally Competent Early Childhood Services for Indigenous Children, Victorian Aboriginal Child Care Agency, Melbourne, 2007.

[45] Andrulis, D.P, Moving beyond the Status Quo in Reducing Racial and Ethnic Disparities in Children's Health, Public Health Reports / July-August 2005 / Volume 120, pp $370-$ $377,2005$.

[46] O’ Hagan K., Cultural Competence in the caring professions. Jessica Kingsley, London, 2001.

[47] Gerrish K. \& Papadopoulos I., Transcultural competence: The challenge for nurse education. British Journal of Nursing 8 (21), 1453-1457, 1999.

[48] Mbabazi, Tad, A Friendly Guide to Research and Research Methods, Jotain Co Ltd, Kampala, 2008.
[49] Yalom, I., Existential psychotherapy, Basic Book, New York, 1980.

[50] Yalom, Marilyn, A History of the Wife. Harper Collins, 2001.

[51] Engel, George L., The need for a new medical model: A challenge of biomedicine" science Journal 196:129-136, 1977.

[52] Engel, George L., The need for a new medical model: A challenge of biomedicine" science Journal 196:129-136, 1977.

[53] Engel, George L., The need for a new medical model: A challenge of biomedicine" science Journal 196:129-136, 1977.

[54] Engel, George L., The need for a new medical model: A challenge of biomedicine" science Journal 196:129-136, 1977.

[55] Jan Christiaan Smuts, Holism and evolution., Macmillan, New York, 1926.

[56] C, L. and W. G, Greater than the parts: holism in biomedicine, Oxford University Press, New York, 1998.

[57] Krishna, Anirudh, Active Social Capital. Tracing the Roots of Development and Democracy, New York, 2002.

[58] Krishna, Anirudh, Active Social Capital. Tracing the Roots of Development and Democracy, New York, 2002.

[59] Krishna, Anirudh, Active Social Capital. Tracing the Roots of Development and Democracy, New York, 2002.

[60] Bennett, Tony, Differing Diversity: Cultural Policy and Cultural Diversity, Strasbourg, Council of Europe Publishing, 2001.

[61] Bennett, Tony, Differing Diversity: Cultural Policy and Cultural Diversity, Strasbourg, Council of Europe Publishing, 2001.

[62] 203. Bhengu M. J, Ubuntu: The Essence of Democracy, Novalis Press, 1996.

[63] Ssekate V. An Anthropological reflection on a Human Person as a living subjective self, Stanford University Press, Italy, 2010.

[64] Henry, Michel, I am the Truth: Towards a Philosophy of Christianity, England, 2003.

[65] Manen M., V, Researching Lived experience: Human Science for an action sensitive pedagogy, The State University of New York, United States of America, 1990.

[66] Manen M., V, Researching Lived experience: Human Science for an action sensitive pedagogy, The State University of New York, United States of America, 1990.

[67] Manen M., V, Researching Lived experience: Human Science for an action sensitive pedagogy, The State University of New York, United States of America, 1990.

[68] Cassano D., R, Social work with multifamily group, Haworth press, United States of America, 1989.

[69] Bettocchi Guillermo, Social Counselling and Social Work with Clients and Their Families in the Somali Context, A facilitator's guide, Somali, 12UNHCR The UN Refugee agency, 2009. 